\title{
LA SOLUCIÓN DEL PROBLEMA DE LA ESCRITURA PERUANA \\ Victoria De La Jara
}

Según opinión muy difundida, tanto en el Perú como en el extranjero, las antiguas civilizaciones peruanas no habrían alcanzado la invención de las escritura. El presente artículo sostiene una tesis opuesta y afirma que los sistemas peruanos de escritura son los más antiguos del continente americano. El análisis del material arqueológico, las citas de los cronistas de los siglos XVI y XVII y ciertas palabras de los vocabularios quechuas antiguos, apoyan esta tesis.

Las pruebas que he recopilado han parecido convincentes a ilustres científicos extranjeros, especialistas en la materia y constituyen el inicio de un estudio que había quedado postergado en el Perú por la falta de cátedras universitarias y de investigadores consagrados al análisis de los problemas de las escrituras primitivas.

\section{EL IMPERIO DE LOS INCAS}

Como veremos más adelante, el uso de la escritura fue muy anterior al imperio de los Incas, que comienza aproximadamente en el año 1350 y termina en el año 1532 con la conquista española, que debió su éxito al hecho de que el Perú estaba dividido por una sangrienta guerra civil.
Hay que recordar que el imperio incaico abarcaba, además del territorio peruano actual, tierras que hoy pertenecen a Bolivia, Ecuador, Chile y Argentina. Los conquistadores incas difundieron sus leyes, sus costumbres, su lenguaje y sus técnicas, pero supieron aprender mucho de los pueblos vencidos.

Estos pagaban un tributo y estaban incluidos en lo que hoy llamaríamos un plan general de desarrollo. Los chasquis (mensajeros pedestres) se alternaban para trasmitir las noticias o las órdenes hasta las fronteras del imperio. ¿Se confiaba solamente en su memoria?, ¿No se vio el peligro de que corrieran por territorios recién conquistados? No lo creo. Tampoco me parece que las leyes del Cusco se aplicaran a todo el imperio sin existir textos. Este problema ya preocupó al cronista Acosta, que sin embargo se encuentra entre los que han negado la existencia de la escritura peruana. Acosta escribe: “...podrá con razón dudar alguno como tenían noticia de todos sus reinos, que eran muy grandes, los reyes de Méjico y del Perú; o que modo de despacho daban a negocios que ocurrían a su corte, pues no tenían letras ni escribían cartas; a esta duda se satisface con saber que de palabra o por pintura o memoriales se les daba muy a menudo razón de todo cuanto se ofrecía" (Hoy sabemos que las "pinturas" mexicanas son los diferentes sistemas de escritura que existieron en ese país). 
Para los eruditos españoles de aquellas épocas, solo una escritura con "letras" era una verdadera escritura. José de Acosta afirma que la escritura china es una "pintura" por carecer de ellas, y ahora comprendemos que fueron en el Perú los "testamentos dibujados", la "historia pintada" y las "señales" para conocer y aplicar las leyes.

Debemos destacar que fue en el siglo XIX -al descifrarse las escrituras egipcias y de Mesopotamia- cuando se descubrió el valor fonético de los jeroglíficos. Dejaron de considerarse "escritura simbólica" y nació en Europa la ciencia de las escrituras primitivas. Todo lo escrito antes de esta fecha debe interpretarse considerando su grave problema cronológico. Los grandes sistemas de escritura de Sumeria, Egipto, Babilonia, Asiria, Creta, el Indo, Hititas, Mayas y Aztecas son como los sistemas de escritura peruanos: "escritura sin letras". Y los inventores de las letras no son los inventores de la escritura.

Pero los limitados conocimientos de la época no impidieron que se reconociera oficialmente el valor documental de las "pinturas" peruanas y en la Real Cédula al Presidente y Oidores de la Audiencia Real de las Provincia del Perú, de fecha 20 de diciembre de 1553, se lee: "Y demás de la información que hubiéredes de los testigos haréis traer ante vosotros cualquier pintura o tablas u otra cuenta que haya de aquel tiempo por do se pueda averiguar lo que está dicho". La Real Audiencia testifica su conocimiento de que por las "pinturas o tablas" peruanas se podía confirmar una declaración verbal anterior.

\section{Estudio del MATERIAL INCA}

En el año 1962 inicié una investigación integral de los materiales arqueológicos y textos que podían ayudar a identificar y reconstruir la escritura perdida de los Incas. Del análisis de los antiguos vocabularios quechuas y las crónicas surgió el dato coherente de la existencia de una escritura con signos de colores y que los tejidos sirvieron como base principal para los textos. Solo faltaba identificar estos signos con el material arqueológico.
El cronista Martín de Morúa al referirse a la forma exterior de los signos Inca dice que Atahualpa tenía: “...un signo como de escribir cuadrado los llamados 'tocapus Inca', son cuadrados y forman conjuntos con características de textos: falta la simetría, aspecto 'caótico' en conjunto, pero con 'combinaciones meditadas". Pudimos apreciar como los mismos signos se repetían parcialmente en diferentes textos o en uno mismo, y encontramos muchas veces la "cruz atravesada" descrita por Morúa. No cabía duda, los tocapus eran los signos de la escritura Inca. (Fig. 1).

En el año 1966 pudimos estructurar el primer catálogo de signos Inca. Hay en él 294 signos diferentes (Figs. 2 y 3). Hasta ahora hemos registrado más de 350 , pero calculamos que su número fue inferior a los 500 o 600 superando a la Cultura Maya, cuya escritura alcanzó 400 signos aproximadamente.

Los Keros con inscripciones facilitaron los primeros desciframientos de la escritura inca. El catálogo de signos de los keros, que estamos estructurando tiene ya cerca de 200 signos, a parte de las variantes de color. Más adelante nos referiremos a estos signos.

No existe notación numérica dibujada en el Imperio Inca. Esto también concuerda con los relatos de los cronistas. Bernabé Cobo habla claramente del doble sistema de "quipus y pinturas", de modo que los documentos incas estaban registrados en los quipus, desde el punto de vista contable y los textos con signospalabra.

De acuerdo a las técnicas modernas, el número de signos permite determinar el tipo de escritura, de allí que los catálogos que hemos estructurado -los primeros que existen- cobren mayor importancia y utilidad.

Al conocer el material con que habíamos trabajado, el famoso científico francés, Marcel Cohen, opinó en 1966, que "de acuerdo al número de signos y en razón de sus alineamientos sobre ciertos documentos, me parece evidente que estamos ante una verdadera escritura, quizá ideo-fonográfica, como la de Egipto y Mesopotamia". 


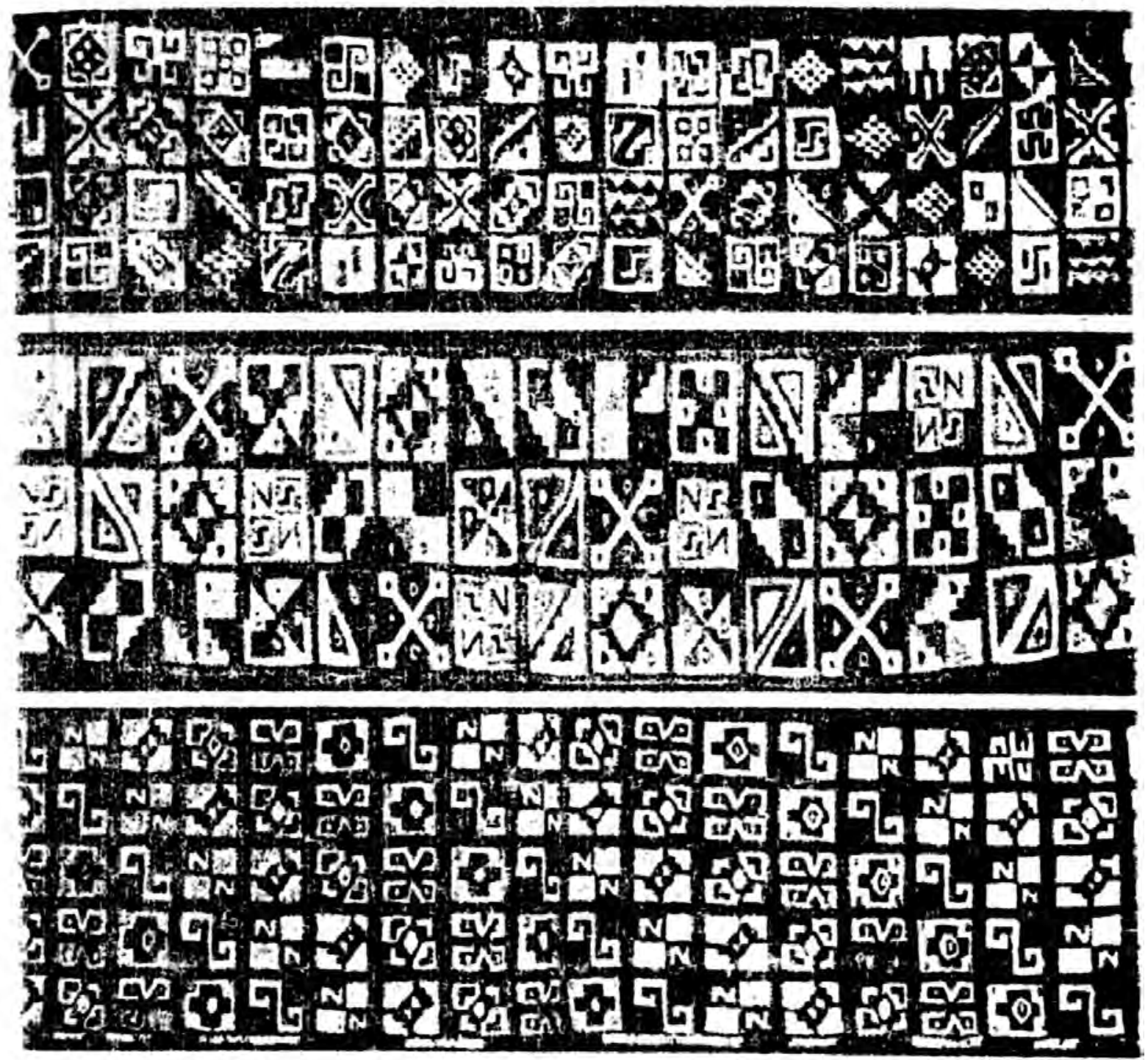

Fig. 1.- Fragmentos de la cintura, de túnica de los Incas. Se observa "cruces atravesadas" dispuesta en una simetría oblicua con interrupción por otros signos. Ejemplares del Museo Arqueológico del Perú, del Museo de Etnología de Berlín y del Museo de Historia Natural de Nueva York. 


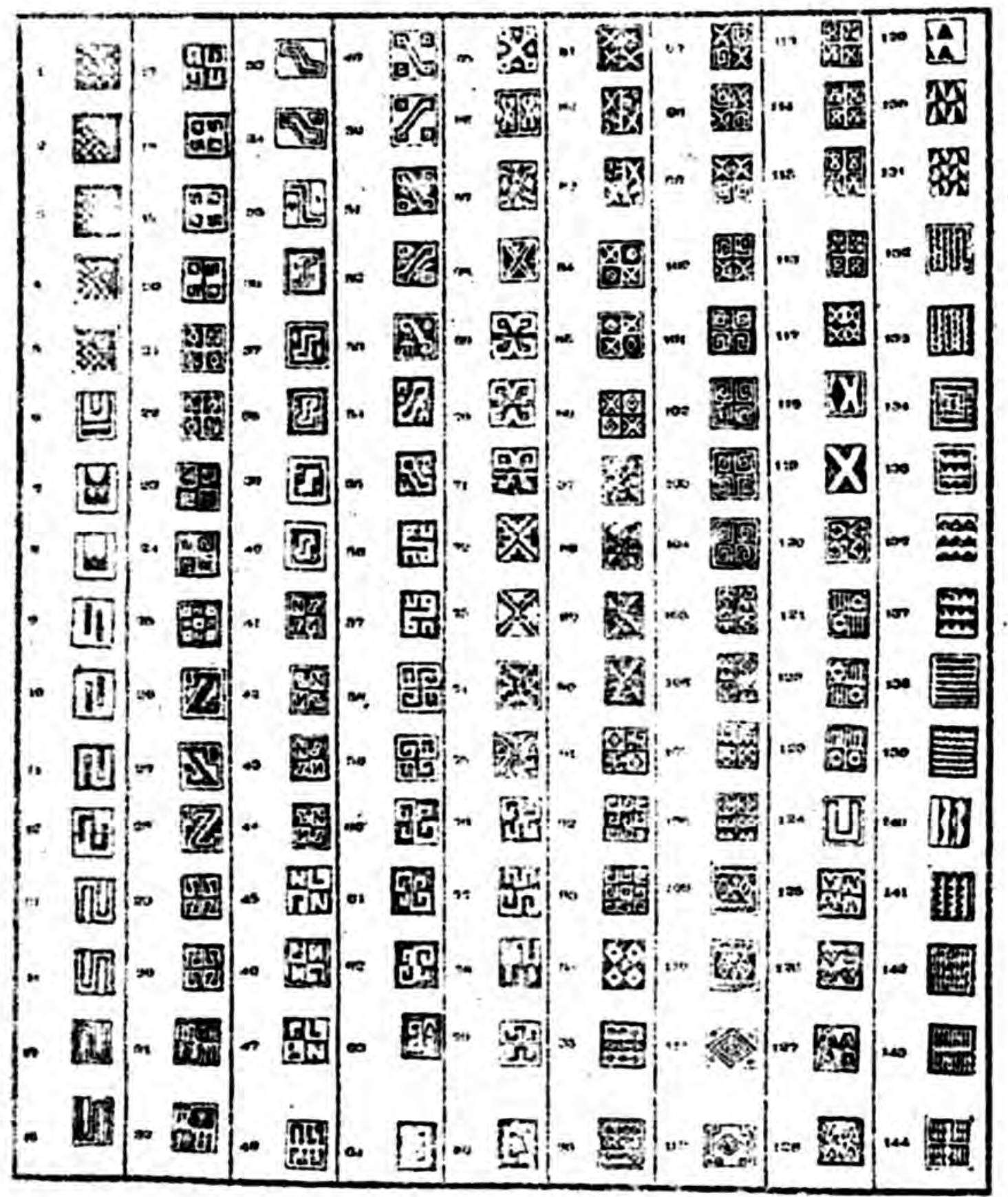

Figs. 2 y 3.- Cuadros de signos Inca. En estas dos figuras se dan 294 signos de la "escritura" inca, tal como el autor los encontró sobre diferentes objetos arqueológicos. La mayor parte de estos objetos son con decorado de un colorido muy rico. Cada uno de los colores empleados por civilizaciones antiguas del continente Americano tenía en general un valor simbólico. Junto con los signos se presenta el Kipu, sistema de numeración (Explicaciones en el texto). 


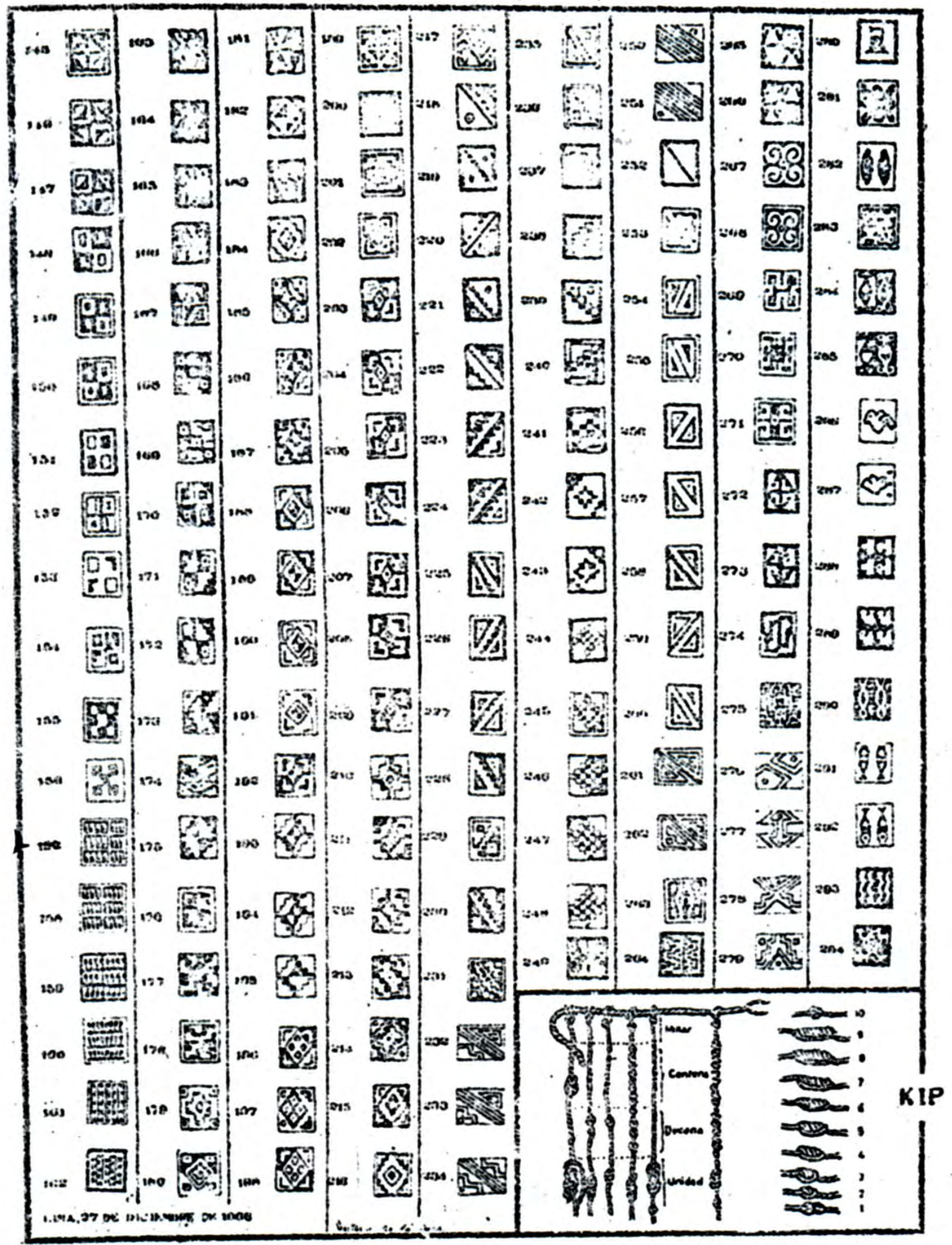




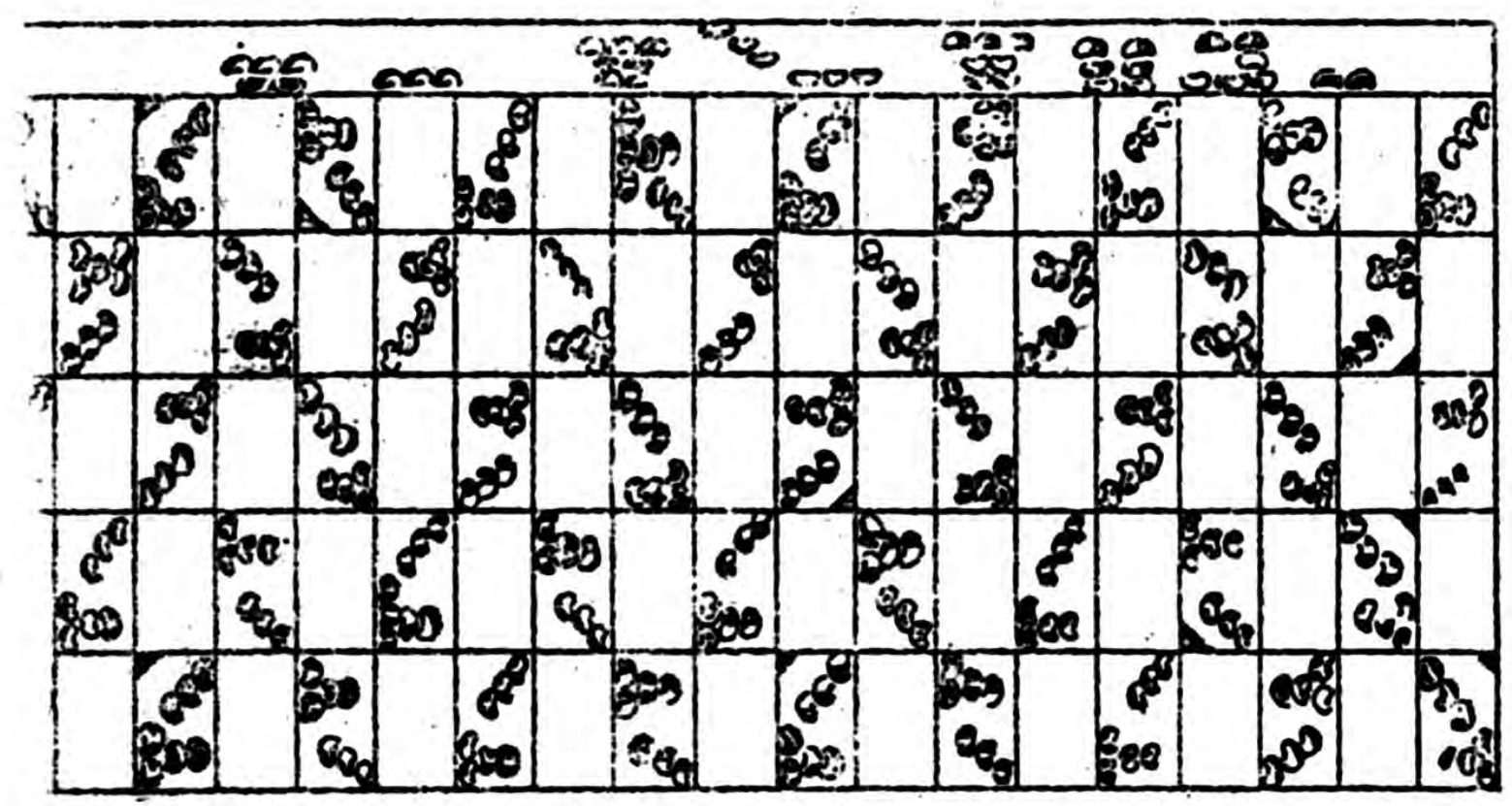

Fig.4.- Inscripción sobre un "manto" funerario de la civilización Paracas.

Cada casillero contiene una serie distinta de signos-pallar

(Museo Nacional de Arqueología y Antropología de Lima)

Fig.5.- Imagen Paracas con signos pallar.

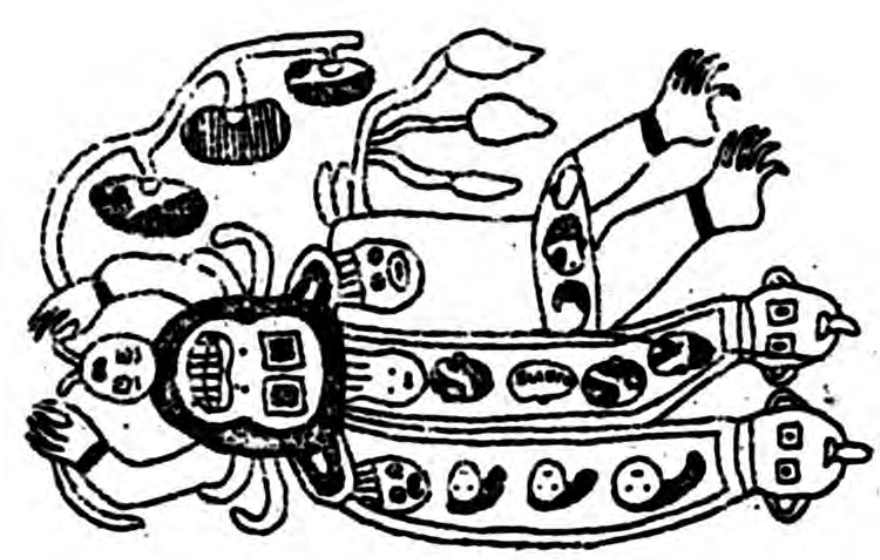




\section{Las Telas Funerarias de Paracas}

El imperio Inca debe mucho a las varias civilizaciones peruanas que lo precedieron, tanto en lo que concierne a escritura como a cultura en general. Prueba de ello son las telas funerarias de Paracas, vestigios de una civilización muy antigua, cuyos dioses y dignatarios ostentan siempre los frutos más óptimos para las tierras recién irrigadas. De estos frutos son el pallar y el fríjol, los que "forman tierra". Creo que a este hecho se debió su gran simbolismo mágico-religioso en las culturas costeñas. Testimonio de ello sería el hecho de haber encontrado en el fardo funerario № 91 (MNAA), no una momia, sino un costal de frijoles envueltos en ricas telas bordadas, con las insignias y ofrendas de los grandes dignatarios de Paracas.

El Museo Nacional de Antropología y Arqueología de Lima, tiene la mayor colección de las telas que cubrían las momias de Paracas, y ellas son testimonio indiscutible de que los peruanos conocían la escritura desde el siglo III a. C.

Durante 21 meses trabajamos en copiar los signos de dichas telas y estructurar el catálogo en el que registramos 298 signos diferentes. Todos son signos-pallar (Fig. 4). Un trabajo posterior hecho con telas de Lima y Nueva York, nos permitió encontrar 25 signos más. Considerando que los signos de Paracas son duales, se puede anticipar que su número no fue inferior a 400 o 500. Debo añadir que al estructurar el catálogo ya mencionado, identificamos los signos-cifra de Paracas, que es un sistema vigesimal y también signos-pallar marcados con puntos.

El testimonio de las telas Paracas destruye la arbitraria afirmación de que en el Perú no había textos ni inscripciones. De las casi 50 telas que analizamos pudimos descubrir, entre otras cosas, que en las telas con signos, las imágenes idénticas van acompañadas de textos diferentes, siendo esta la única variación de forma apreciable. El mejor testimonio que hallamos fue una tela de Paracas con 23 felinos idénticos y extensas inscripciones diferentes.

En Paracas, como en el Imperio Inca, hay una escritura con signos de colores sobre teji- dos. En ambos casos es frecuente ver los signos en la cintura de los vestidos. (Fig. 5). En los antiguos vocabularios quechuas existe la palabra quellcascappacha cuya traducción literal es "vestido escrito". Vestidos de ese tipo, es decir, con signos, existen también en otras culturas antiguas, como la egipcia.

Afamados científicos extranjeros examinaron nuestros trabajos. Así el profesor de Alemania, Thomas S. Barthel, quien me escribió las siguientes líneas: "Permítame felicitarla por el espléndido descubrimiento que ha logrado en los pasados años en el análisis de los textiles de Paracas. Ud. ha presentado ambos: la evidencia y el sistema Paracas".

Los sistemas de escritura de mayor importancia y más conocidos son los de Paracas e Incas, siendo éstos, el principio y el fin de nuestras escrituras. Las etapas intermedias van surgiendo con graves problemas, pero al ser ya indiscutible la existencia de la escritura en el Antiguo Perú, las otras evidencias son también aceptadas por los científicos.

\section{El Problema de las Escrituras CON SignOs-PAllaR}

Hace más de 30 años el arqueólogo peruano Rafael Larco Hoyle expuso la teoría de que los peruanos antiguos habrían escrito sobre pallares, siendo éstos pequeños textos. Desgraciadamente, los dibujos y fotografías que publicó inspiraron la teoría de los pallares como "fichas de juego". Podemos ver aún que los personajes mochicas agrupan pallares con dibujos idénticos. Toda inscripción alfabética o pre-alfabética, exhibe un agrupamiento de signos diferentes, y la selección de pallares con dibujos iguales parecen señalar un juego.

Mi teoría es una investigación independiente y no la continuación de los trabajos realizados por Larco Hoyle. Fueron las telas Paracas del Museo Nacional de Lima, las que me permitieron presentar pruebas de una escritura temprana con signos-pallar. Al conocer mi trabajo, el profesor Barthel, catedrático de Escrituras Primitiva de la Universidad de Tübingen me escribió, diciendo: "Usted ha hecho 
añicos la anterior explicación que consideraba los pallares como fichas de juego, y gustoso estoy de corregir mi posición anterior".

Los resultados comparativos de nuestra investigación sobre las escrituras con signospallar, son las siguientes:

1. Hay 4 escrituras con signos-pallar: Paracas, Nasca, Mochica A y Mochica B. (Fig.6).

2. Es evidente que Mochica A y Mochica B son dos sistemas diferentes, teniendo el segundo signos de mayor complejidad y asemejándose parcialmente al sistema Inca. El estudio de la escritura Mochica ofrece la dificultad de haber muy pocos objetos arqueológicos de auténtico interés.

3. No hay testimonios suficientes para afirmar que los sistemas de Paracas, Nasca y Mochica A son idénticos. Podrían coincidir en la forma del signo-pallar y revelar un proceso de evolución. Las diferencias cronológicas y de lenguaje no pueden ser desestimadas en ningún caso.

4. Un análisis de numerosos vasos con cifras existentes en el Museo Nacional, nos dieron el testimonio de que los signos-cifra de Paracas y Mochica A son iguales. Esta constatación solo es válida para las cifras.

5. Tenemos las primeras evidencias de un segundo sistema de cifras Mochica, cuyos signos parecen inspirados en el Quipu. Lo he titulado Mochica B. El uso simultáneo de varias escrituras es frecuente en otras culturas antiguas.

6. El problema Nasca es muy grave, pero su escritura es la más importante después de Paracas e Inca. Los personajes de Nasca tienen vestidos e insignias bastante similares a los de Paracas, pero con los signos de su escritura pocas veces están asociados a estos dignatarios. Es frecuente la aparición de signos sin personajes, y en Paracas solo he visto una tela con signos y sin personaje.

En Nasca vemos un cambio en la forma del signo-pallar. Uno de sus lados se convierte en ángulo. Y los primeros "signos cuadrados" son pallares Nasca. Las cifras Nasca son aún más conflictivas: los puntos señalan cifras más elevadas que el 20, pero descubrí otro sistema formado por signos- cifra de diseño peiniforme, que aparecen solos o asociados a líneas horizontales, que también aparecen solas. Un gran número de piezas de cerámica del Museo Nacional dan esta evidencia. Hay allí un tambor con estos nuevos signos-cifra, y hago la observación de que una tableta de Mesopotamia clasificada como "matemática" ha revelado una notación musical. El nuevo sistema de signos peiniforme evoca también la forma del Kipu y es quizá el primer sistema decimal del Perú.

7. Con una diferencia radical de los signoscifra, Mochica y Nasca tienen numerosos ceramios cubiertos por ellos. Aún no se conoce su significado.

\section{La Escritura Prohibida}

El cronista Montesinos habla claramente de una escritura prohibida. El estudio del material arqueológico revela la desaparición definitiva de los signos-pallar cuando la cultura Wari se extiende por la Costa. ¿No hay escritura Wari o Tiahuanaco? ¿No hay escritura entre Mochica B y los Incas? Tenemos ya los primeros testimonios de su existencia: signos Inca con esquematizaciones de signos Tiahuanaco. Hallé dos inscripciones Wari cuyos signos cuadrados se parecen a los signos-pallar, y el pequeño vaso de arcilla en forma de kero descubierto en la fortaleza de Sacsahuamán tiene signostocapu que parecen ser los antepasados de los signos Inca, que vemos en tejidos y Keros. Nuevos descubrimientos arqueológicos irán completando este camino sumergido entre lo signos-pallar y los signos-tocapus Inca.

Mi programa básico ha sido reconstruir todo el sistema de escritura del antiguo Perú. Las dificultades son grandes debido a la pérdida masiva de nuestros textos. Hubo una escritura "sobre tejidos”. Pedro Cieza de León dice: “...y si la ropa fina que se desperdició y perdió en aquellos tiempos se guardara, valiera tanto que no lo oso afirmar según tengo que fuera mucho...”. El Virrey Toledo obtiene el dato de que las "tablas de colores" con "señales" usadas para conocer las leyes del Cusco "las quebraron e destruyeron" los españoles. Perdimos los Códigos del Imperio. El pasado también sufrió daño. El pillaje viola 


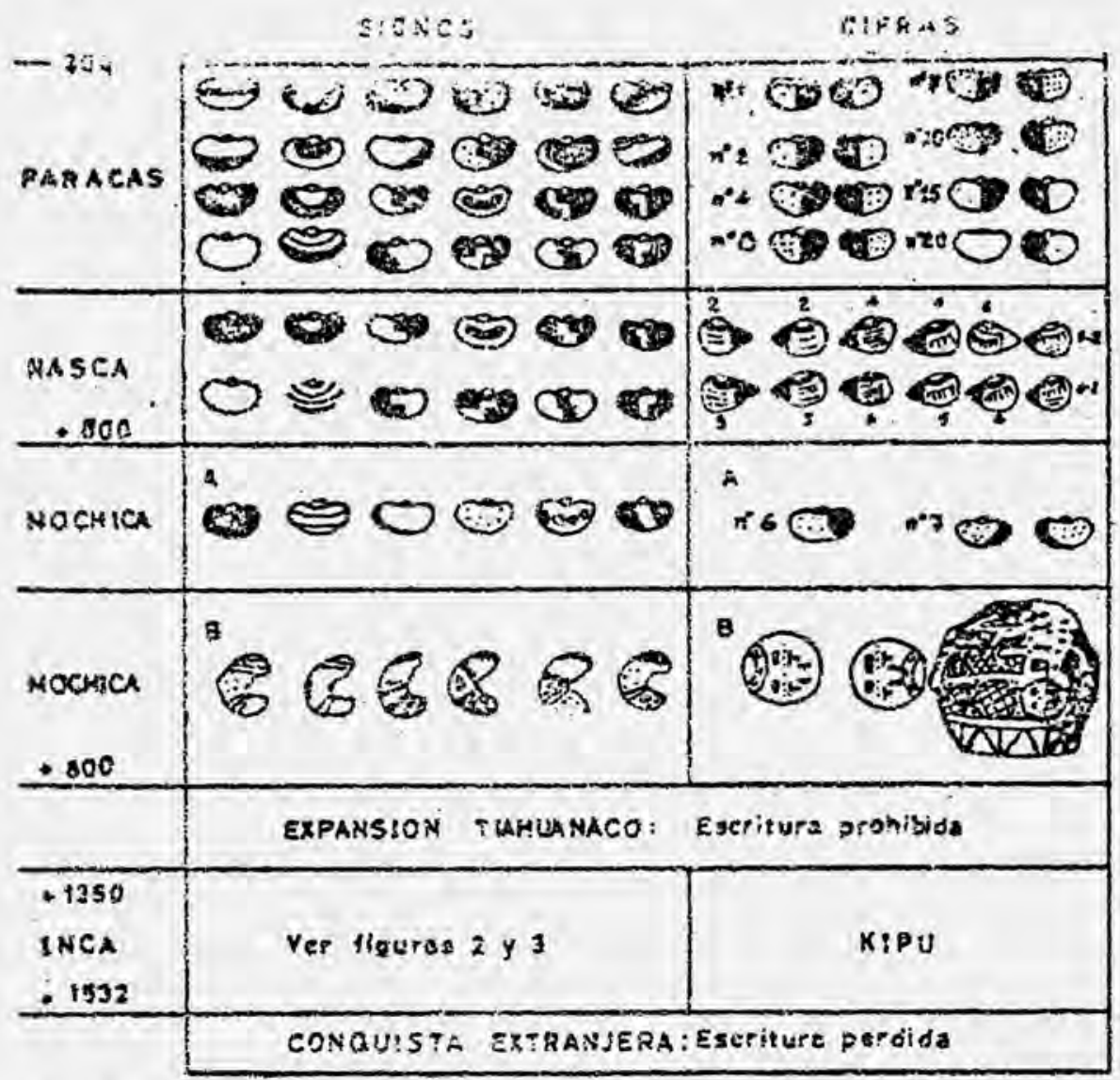

Fig. 6.- Evolución de la antigua escritura peruana.

Alrededor del año 800 de nuestra era, la expansión Tiahuanaco tras la prohibición de la escritura. Alrededor de 1350 aparecería la escritura Inca (ver figura 2 y 3 ) que posiblemente desapareció en 1532 con la conquista española.

Fig. 7.- Dibujo copiado de un Kero, vaso de madera inca.

Kero sin escena, con inscripción de cinco signos que se repiten cuatro veces.

$\mathrm{Al}$ centro, una inscripción de diez signos.

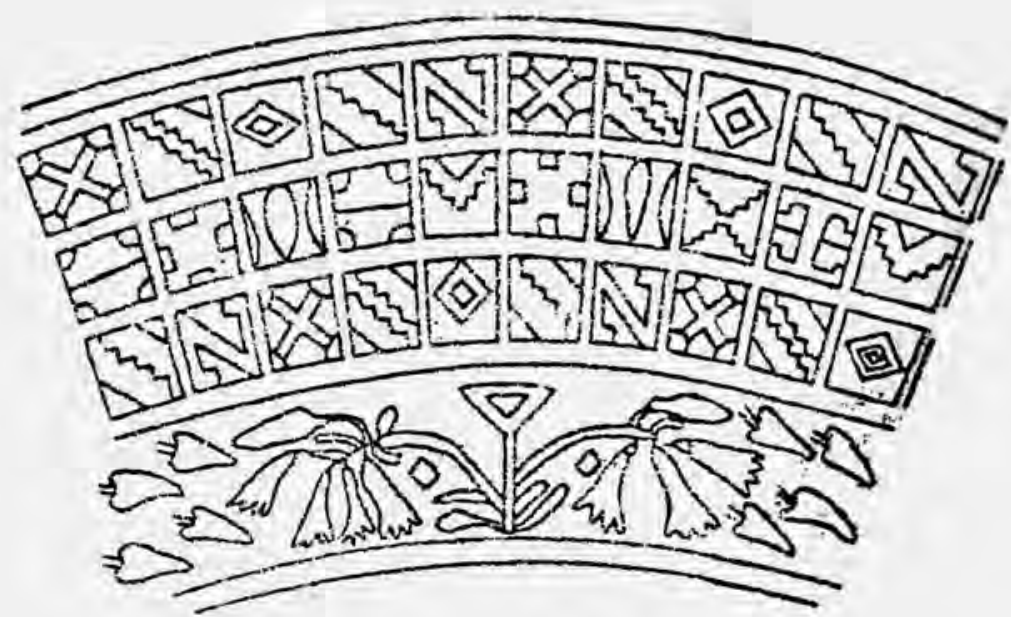


las tumbas y momias envueltas en telas multicolores son destruidas. Hubo tanto, sin embargo, que se salvó mucho.

\section{Hacia el Desciframiento}

De acuerdo con la ciencia contemporánea, toda escritura puede ser descifrada, pero para ello se requieren técnicas complicas y trabajo en equipo, y yo he trabajado siempre absolutamente sola. El profesor Thomas S. Barthel -fundador del Instituto de Etnografía de la Universidad de Tübingen, Alemania- es uno de los más afamados intérpretes de las escrituras Maya e Isla de Pascua. Desde el año 1966 ha recibido todos mis trabajos y en el año 1968 me anunció que la escritura peruana formaría parte del programa de investigaciones de su Instituto, e inició los primeros esfuerzos sistemáticos para el desciframiento de las escritura de los Incas.

Dejé por un tiempo el estudio de los signospallar y dediqué todos mis esfuerzos a los Incas. Lima y Tübingen se unen en un esfuerzo común. Viajan slides con tejidos, keros y pinturas coloniales y múltiples, informes que preparo. El profesor Barthel consigue 30 keros-texto y yo 140. Envío un kero con 64 signos y otro con 48. El № 55 se perfila con el más inquietante. Veo en él las "letras" "groseras y toscas" de las 16 torres usadas por los Incas para conocer los solsticios del verano y del invierno y que Garcilaso describe. El profesor Barthel piensa en otra explicación, pero coincidimos en que estamos ante un nuevo tipo de inscripciones en keros. "Estamos haciendo juntos progresos considerables", me dice en su última carta.

Ciento veinticinco keros-texto me permitieron hacer una clasificación tipológica de ellos. Los resultados son los siguientes: 40 keros-texto sin escenas, 82 keros-texto con escena y 3 keros-texto-felinos. Me parece que la diferencia tipológica de los keros-texto está en vinculación con su valor ritual o evocativo. Los keros sin escenas se dividen en tres clases y los con escena en seis.

Para el desciframiento de la escritura Paracas añadí a mis trabajos anteriores la obser- vación de que son ciertas características de las imágenes -sobre las cuales están los signos- las que señalan la dirección de la escritura. Algunas veces un bustrófedon continúa en toda la tela, pero en otros casos s interrumpe para anudarse otra vez. Este dato puede ser ... para todas las escritura peruanas.

Durante 4 años mi trabajo recibió el consejo y aliento de tres científicos extranjeros: Marcel Cohen de Francia: "Pienso que ya no puede existir discusión sobre el hecho de la escritura peruana.... no esté descifrada. Hay que confiar en el porvenir, que será quizá antes que para la Maya"; Daniel Cazes de México: "Ya no puede existir duda de que se trata de una escritura", y Thomas S. Berthel de Alemania: "Cada vez será más difícil en el futuro, el querer calificar el antiguo Perú como "alta cultura temprana sin ninguna escritura". (Ponencia presentada al $38^{\circ}$ Congreso de Americanistas, Alemania, 1968). Es en 1969 cuando llega la noticia esperada: "Querida Victoria, este es un momento de triunfo, en el mismo momento en que el primer hombre desembarcaba en la luna, aquí en Tübingen, y como si nos cumpliera su antigua promesa de volver, los primeros signos de la escritura Inca, que acabo de descifrar, me escribió el profesor Barthel, nos traen su nombre: Con Ticci Viracocha.

\section{¿Qué es UN KeRo-TeXto?}

Fabricado bajo el despotismo extranjero, el kero-texto no es un ingenuo exponente de rememoraciones sentimentales del pasado. Enigmático en su esencia misma, sus signos ya pueden ser leídos y lo perfilan como el vaso ritual de clandestinos cultos. La escritura Inca testifica la existencia de una página perdida en nuestra historia y se vislumbra un trajinar silencioso de los Amautas.

Detrás del tabernáculo católico aparecen idolitos Incas y santos venerables -rostros con el terremoto- descubren sus signos-tocapu interiores. Solo un 10 ó 15\% de los keros tienen inscripciones. Así mis 140 keros equivalen a 1400 estudiados. Jamás vi una cruz en ellos. Es una rebeldía sistemática, aunque aceptan el caballo, la sirena y la guitarra. (Fig.7). 
Los signos-tocapu no acompañan tampoco son evocados y perennizados en los textos Inca a los santos católicos en la pintura cusqueña "coloniales". Por eso los españoles no se exy los dioses peruanos -tan angustiosamente plicaron el sistema gráfico Inca, y no supieron perseguidos por el "extirpador de idolatrías"- leerlo. 